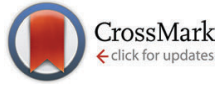

Cite this: Phys. Chem. Chem. Phys., $2015,17,17260$

Received 4th May 2015, Accepted 28th May 2015 DOI: $10.1039 / c 5 c p 02591 e$

www.rsc.org/pccp

\title{
In situ site-selective transition metal K-edge XAS: a powerful probe of the transformation of mixed-valence compounds $\uparrow$
}

\author{
Amélie Bordage, ${ }^{* a}$ Virgile Trannoy, ${ }^{a}$ Olivier Proux, ${ }^{\text {bc }}$ Hugo Vitoux, ${ }^{d}$ \\ Robinson Moulin ${ }^{a}$ and Anne Bleuzen ${ }^{a}$
}

\begin{abstract}
We present herein the first in situ site-selective XAS experiment performed on a proof-of-principle transformation of a mixed-valence compound: the calcination of the $\mathrm{K}_{0.1} \mathrm{CO}_{4}{ }_{4}\left[\mathrm{CO}{ }^{111}(\mathrm{CN})_{6}\right]_{2.7} \cdot 2 \mathrm{OH}_{2} \mathrm{O}$ Prussian Blue analogue (containing $\mathrm{Co}^{2+}$ and $\mathrm{Co}^{3+}$ ions in two different $\mathrm{O}_{\mathrm{h}}$ sites) into $\mathrm{CO}_{3} \mathrm{O}_{4}$ (containing $\mathrm{Co}^{2+}$ ions in a $\mathrm{T}_{d}$ site and $\mathrm{Co}^{3+}$ in an $\mathrm{O}_{\mathrm{h}}$ site). By recording the Co K-edge $\mathrm{X}$-ray absorption spectra using a spectrometer aligned at the Co $K \beta_{1,3}$ emission line, the evolution of each species was singly monitored from $20{ }^{\circ} \mathrm{C}$ up to the oxide formation. The experimental spectrum of the $\mathrm{Co}^{2+}\left(\mathrm{T}_{\mathrm{d}}\right)$ and $\mathrm{Co}^{3+}\left(\mathrm{O}_{h}\right)$ species in $\mathrm{CO}_{3} \mathrm{O}_{4}$ is reported for the first time. Our results demonstrate the possibilities offered by site-selective XAS for the investigation of chemical transformations and the study of materials under working conditions whenever the chemical element of interest is present in several states and/or sites.
\end{abstract}

\section{Introduction}

X-ray absorption spectroscopy (XAS) is a well-known powerful tool to characterize the electronic and crystallographic structure of an element in a compound. In the hard X-ray range, XAS is now routinely performed under extreme conditions (pressure, temperature, and irradiation); in situ $\mathrm{XAS}^{1-7}$ is also a mature technique widely used to study chemical processes. However, the classical detection modes (transmission, total fluorescence and total electron yield) average over all species of the absorbing atom in the sample, which hinders the investigation of compounds with the absorbing atom present under different oxidation/spin states and/or in different sites. Site-selective XAS has recently brought new opportunities since it can overcome this limitation ${ }^{8-10}$ by taking advantage of the high sensitivity of the $K \beta_{1,3}$ emission line of one element to the spin and oxidation states as well as to covalency. ${ }^{11-16}$ The spectra are recorded using a high-resolution Rowland-circle spectrometer with analyzer crystals aligned at the maximum of the $K \beta_{1,3}$ emission line of a

\footnotetext{
${ }^{a}$ ICMMO, Université Paris-Sud, UMR CNRS 8182, Equipe de Chimie Inorganique, Rue du doyen Georges Poitou, 91405 Orsay Cedex, France.

E-mail: amelie.bordage@u-psud.fr

${ }^{b}$ OSUG, UMR CNRS 832, Université Grenoble-Alpes, F-38041 Grenoble Cedex 9, France

CBM30B/FAME, ESRF, Polygone scientifique Louis Néel, 71 avenue des Martyrs, 38000 Grenoble, France

${ }^{d}$ European Synchrotron Radiation Faciliy, Sample Environment Service,

71 avenue des Martyrs, 38043 Grenoble, France

$\dagger$ Electronic supplementary information (ESI) available: The X-ray diffraction pattern of the final phase. See DOI: 10.1039/c5cp02591e
}

given site. The analyzer selects this particular fluorescence line for each incident energy and reflects it on a detector. This technique has been successfully used for instance to discriminate the Co ions from the core and the shell of nanoparticles ${ }^{17,18}$ or to investigate in detail the active site in [FeFe] hydrogenase. ${ }^{19,20}$ Herein, we demonstrate for the first time that this demanding XAS technique can be used for in situ investigations. This opens new perspectives to unravel the mechanisms of chemical processes (redox processes, homogeneous or heterogeneous catalysis,...) and to study materials under working conditions (batteries, catalysts,...), which are everyday challenges for chemists.

As a proof-of-principle study, we chose to follow the calcination in air of the monometallic Prussian Blue analogue (PBA) of formula $\mathrm{K}_{0.1} \mathrm{Co}_{4}{ }_{4}\left[\mathrm{Co}^{\mathrm{III}}(\mathrm{CN})_{6}\right]_{2.7} \cdot 20 \mathrm{H}_{2} \mathrm{O}$ (called Co-PBA) into $\mathrm{Co}_{3} \mathrm{O}_{4} \cdot{ }^{21}$ PBAs are well-known for their face-centred cubic structure made of cyanide bridges linking two transition metals in the three directions of space. $^{22,23}$ In Co-PBA, $\mathrm{Co}^{2+}$ high-spin ions (Fig. 1, orange balls) and $\mathrm{Co}^{3+}$ low-spin ions (Fig. 1, green balls) are both present in an octahedral $\left(\mathrm{O}_{\mathrm{h}}\right)$ site but surrounded by different neighbours: $\mathrm{Co}^{2+}$ is linked to an average of four cyanide bridges (at the $\mathrm{N}$ side) and two water molecules, while $\mathrm{Co}^{3+}$ is linked to six cyanide bridges (at the $\mathrm{C}$ side). The $\mathrm{Co}_{3} \mathrm{O}_{4}$ oxide crystallizes in a direct spinel structure with the $\mathrm{Co}^{3+}$ ions in the $\mathrm{O}_{\mathrm{h}}$ site and the $\mathrm{Co}^{2+}$ ones in the tetrahedral $\left(\mathrm{T}_{\mathrm{d}}\right)$ site; both $\mathrm{Co}$ ions are linked to $\mathrm{O}^{2-}$ ions. In the case of monometallic PBAs, reference compounds are available for each single site. For instance, in the case of Co-PBA, the $\mathrm{Co}^{2+}$ site is analogous to the $\mathrm{Co}$ site in $\mathrm{Co}_{4}{ }_{4}^{\mathrm{I}}\left[\mathrm{Fe}^{\mathrm{III}}(\mathrm{CN})_{6}\right]_{2.7} \cdot 20 \mathrm{H}_{2} \mathrm{O}$ PBA, while the $\mathrm{Co}^{3+}$ site resembles that in $\mathrm{Fe}^{\mathrm{II}}{ }_{4}\left[\mathrm{Co}^{\mathrm{III}}(\mathrm{CN})_{6}\right]_{2.7} \cdot 20 \mathrm{H}_{2} \mathrm{O}$ PBA. However, in the case of the $\mathrm{Co}_{3} \mathrm{O}_{4}$ spinel or the transient states, such reference compounds 


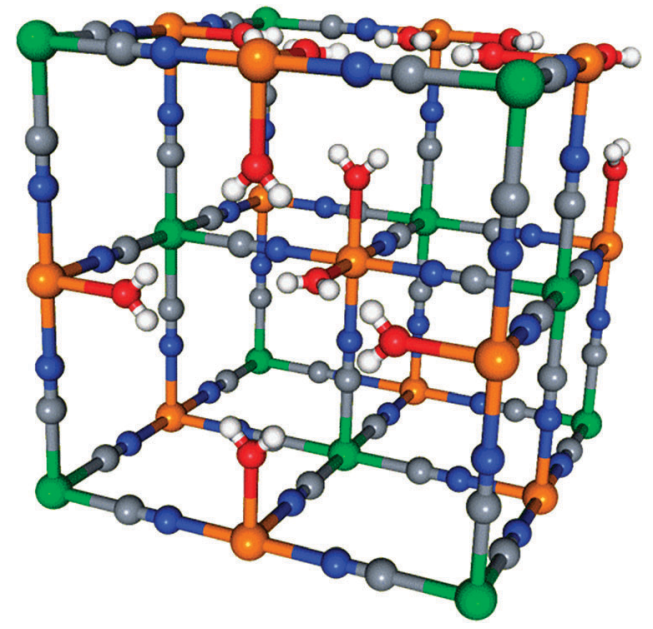

Fig. 1 Unit cell structure of Co-PBA showing the two possible Co sites. The $\mathrm{Co}^{2+}$ ions are in orange and the $\mathrm{Co}^{3+}$ ones in green. The grey balls represent the $\mathrm{C}$ atoms, the blues ones the $\mathrm{N}$ atoms, the red ones the $\mathrm{O}$ atoms inside a water molecule.

are unavailable. The calcination of Co-PBA into $\mathrm{Co}_{3} \mathrm{O}_{4}$ is therefore an ideal case to test the opportunities offered by in situ siteselective XAS to follow complex chemical processes since at least four different sites are involved in the transformation $\left(\mathrm{Co}^{3+}-\mathrm{CN}\right.$ $\left.\left(\mathrm{O}_{\mathrm{h}}\right), \mathrm{Co}^{2+}-\mathrm{NC}\left(\mathrm{O}_{\mathrm{h}}\right), \mathrm{Co}^{3+}-\mathrm{O}\left(\mathrm{O}_{\mathrm{h}}\right), \mathrm{Co}^{2+}-\mathrm{O}\left(\mathrm{T}_{\mathrm{d}}\right)\right)$ and the calcination completely redistributes the Co species. In this contribution we concentrate on the XANES (X-ray Absorption Near-Edge Structure) part of the X-ray absorption spectrum.

\section{Experimental}

\section{Materials}

Co-PBA $\left(\mathrm{K}_{0.1} \mathrm{Co}_{4}{ }_{4}^{\mathrm{II}}\left[\mathrm{Co}^{\mathrm{III}}(\mathrm{CN})_{6}\right]_{2.7} \cdot 20 \mathrm{H}_{2} \mathrm{O}\right)$ and a reference ex situ sample (obtained by the calcination of Co-PBA in air during $2 \mathrm{~h}$ hours at $900{ }^{\circ} \mathrm{C}$, and called exsitu) were synthesized as described in ref. 21. The two $\mathrm{Co}_{4}\left[\mathrm{Fe}(\mathrm{CN})_{6}\right]_{2.7} \cdot 20 \mathrm{H}_{2} \mathrm{O}$ (called $\mathbf{C o}^{2+}-\mathbf{N}$ ) and $\mathrm{Rb}_{2} \mathrm{Co}_{4}\left[\mathrm{Fe}(\mathrm{CN})_{6}\right]_{3.3} \cdot 11 \mathrm{H}_{2} \mathrm{O}$ (called $\mathbf{C o}^{3+}-\mathbf{N}$ ) PBAs used as references were prepared as described in ref. 24. The other two reference compounds, $\left[\mathrm{Co}\left(\mathrm{OH}_{2}\right)_{6}\right]\left(\mathrm{NO}_{3}\right)_{2}$ (called $\left.\mathbf{C o}^{2+}-\mathbf{O}\right)$ and $\mathrm{K}_{3}\left[\mathrm{Co}(\mathrm{CN})_{6}\right]$ (called $\mathbf{C o}^{3+}-\mathbf{C}$ ), were supplied by Sigma-Aldrich.

\section{X-ray spectroscopy}

Co K-edge XANES spectra were recorded on the CRG-FAME (BM30B) beamline of the ESRF (Grenoble, France) using their five-crystal spectrometer. ${ }^{25}$ The energy of the incident radiation was selected using a pair of $\operatorname{Si}(220)$ crystals (flux of $c a .5 .10^{11}$ photons $\mathrm{s}^{-1}$ ). Co $\mathrm{K} \beta$ site-selectivity was performed by recording the XANES spectra with spherically bent Ge(444) crystals in a Rowland geometry. The detector was a Silicon Drift Detector (energy resolution: $250 \mathrm{eV}$ ) in order to discriminate the signal diffracted by the crystals from the scattered one and so to improve the signal-to-noise ratio. Self-absorption effects were ruled out by diluting Co-PBA in $\mathrm{BN}$ and we checked that no radiation damage occurred by recording fast spectra as a

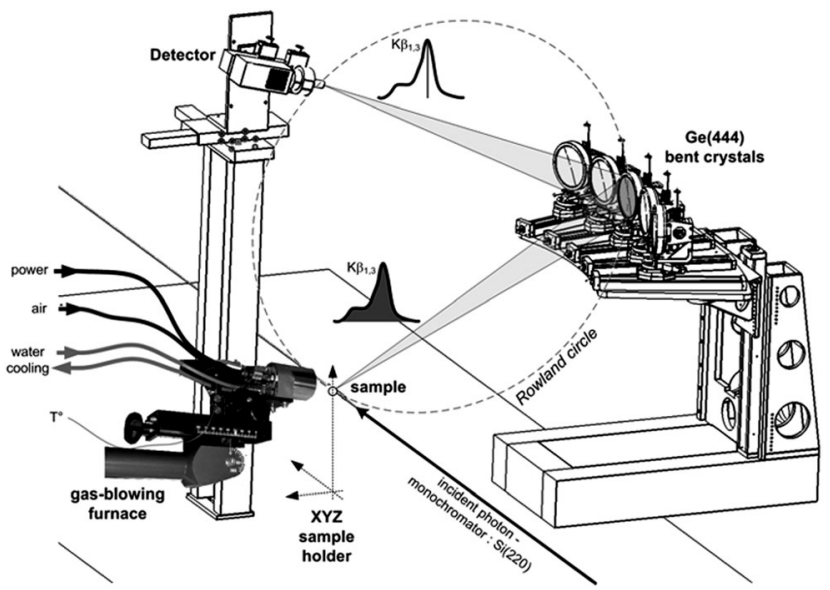

Fig. 2 Experimental setup on the FAME beamline (BM30B, ESRF) for in situ site-selective XAS measurements.

function of time. The combined resolution of the incident beam and the spectrometer was $\Delta E=0.6 \mathrm{eV}$, measured from the pseudo-elastic peak full-width at half-maximum. Spectra were simultaneously recorded in the transmission mode. The in situ calcination was achieved using a Cyberstar gas-blower furnace. Calibration of the furnace was performed prior to measurements and the temperature stability was checked during measurements. This setup is illustrated in Fig. 2.

The X-ray emission spectrum of $\mathbf{C o}^{2+}-\mathbf{O}$ (resp. $\mathbf{C o}^{3+}-\mathbf{C}$ ) was recorded at room temperature and was used to align the spectrometer for the +II (resp. +III) oxidation state. Data were acquired at seven temperatures from room temperature up to $400{ }^{\circ} \mathrm{C}$. In the following text, only the spectra corresponding to the most relevant temperatures for the discussion $\left(20^{\circ} \mathrm{C}, 145{ }^{\circ} \mathrm{C}\right.$ and $400{ }^{\circ} \mathrm{C}$ ) are presented; for better clarity, the temperature is now specified next to the Co-PBA name (Co-PBA@temperature). For each temperature at which Co-PBA was investigated, a Co $\mathrm{K} \beta_{1,3} \mathrm{X}$-ray emission spectrum and Co $\mathrm{K}$ - edge X-ray absorption spectra for the two positions of the spectrometer were recorded. The X-ray absorption spectra of Co-PBA and of the references were also recorded in transmission mode at each investigated temperature.

\section{Results and discussion}

\section{Formation of the targeted phase}

In order to attest the formation of the targeted $\mathrm{Co}_{3} \mathrm{O}_{4}$ phase during the in situ calcination process, the Co K-edge spectrum of exsitu was recorded. It is compared to the transmission spectrum of Co-PBA@400 ${ }^{\circ} \mathrm{C}$ in Fig. 3. A very good agreement is observed both between them and the $\mathrm{Co}_{3} \mathrm{O}_{4}$ spectra reported in the literature and in particular the maximum of the white line at $7729.4 \mathrm{eV} .^{18,26,27}$ This agreement attests that the targeted $\mathrm{Co}_{3} \mathrm{O}_{4}$ phase was produced during the in situ chemical transformation of Co-PBA; this is also confirmed by X-ray diffraction (see $\mathrm{ESI} \dagger$ ). Therefore, the information obtained from the spectra recorded at the different temperatures actually reflects the processes involved in the calcination described in ref. 21. 


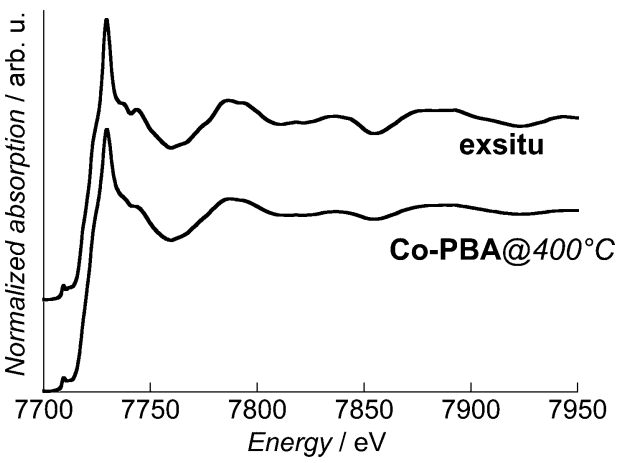

Fig. 3 Normalized Co K-edge XANES spectra in transmission mode of Co-PBA@ $400{ }^{\circ} \mathrm{C}$ and exsitu.

The slight differences in the relative intensities can be explained by a lower crystallinity for the in situ sample due to the lower temperature of calcination.

\section{In situ X-ray emission spectroscopy}

A high-resolution spectrometer such as the one on FAME $^{25}$ also enables us to perform X-ray emission spectroscopy (XES). This technique is well-known for its high-sensitivity to the spin state of transition metal ions ${ }^{11-16}$ and can be performed in situ. ${ }^{1,2,28-30}$ The Co $\mathrm{K} \beta_{1,3}$ X-ray emission spectra of Co-PBA as a function of temperature are displayed in Fig. 4, as well as the spectrum of exsitu. A shift of the maximum towards higher energy is observed upon heating and reveals a change in the Co species during the calcination process. However, it becomes clear that XES reaches a limit for the study of transformations in multisite compounds. The changes observed with the temperature are indeed (i) too small to enable a precise determination of the changes in the Co environment and (ii) averaged over the different species.

\section{Extraction of the $\mathrm{Co}^{2+}$ and $\mathrm{Co}^{3+}$ pure contributions}

The Co K $\beta_{1,3} \mathrm{X}$-ray emission spectrum of Co-PBA@20 ${ }^{\circ} \mathrm{C}$ is shown in Fig. 5a, along with those of the $\mathbf{C o}^{2+}-\mathbf{O}$ and $\mathbf{C o}^{3+}-\mathbf{C}$ references for the two sites of Co (called simply as $\mathrm{Co}^{2+}$ and $\mathrm{Co}^{3+}$ sites in the following text) in this compound. The important feature here is the shift in energy of the $\mathrm{K} \beta_{1,3}$ line maximum from $7650.6 \mathrm{eV}$ for $\mathbf{C o}^{2+}-\mathbf{O}$ down

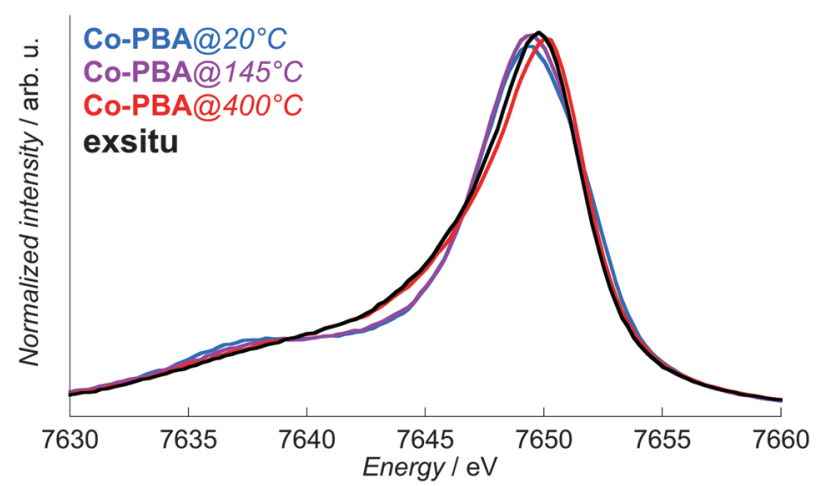

Fig. 4 In situ normalized Co $K \beta_{1,3}$ X-ray emission spectra of Co-PBA $\triangle 20{ }^{\circ} \mathrm{C}$, Co-PBA $\curvearrowright 145^{\circ} \mathrm{C}$ and Co-PBA $\left(400{ }^{\circ} \mathrm{C}\right.$, presented with the spectrum of exsitu. to $7649 \mathrm{eV}$ for $\mathbf{C o}^{3+}$-C. XANES spectra were therefore successively recorded using a spectrometer aligned at these two energies. However, it is clear from Fig. 5a that experimentally, one cannot record a pure site-selective X-ray absorption spectrum: whatever the energy chosen for the spectrometer, the spectrum includes a contribution from both sites. The pure $\mathrm{Co}^{2+}$ and $\mathrm{Co}^{3+}$ contributions for each temperature must consequently be extracted from the measured spectra at the two energies of the spectrometer. We describe now this procedure, which is illustrated in Fig. 5 for the $20{ }^{\circ} \mathrm{C}$ measurement. In the following text, the term 'K $\beta$-HERFD X-ray absorption spectrum' refers to the spectrum measured using the spectrometer, while the term 'site-selective spectrum' refers to the 'pure' $\mathrm{Co}^{2+}$ and $\mathrm{Co}^{3+}$ extracted contribution. The reader should keep in mind that the pure term is used here with the understanding that the spectra it refers to are obtained after deconvolution of two experimental spectra and were not directly measured as real pure spectra.

First, from a linear combination of the normalized X-ray emission spectra of $\mathbf{C o}^{2+}-\mathbf{O}$ and $\mathbf{C o}^{3+}-\mathbf{C}$ wherein the $\mathrm{Co}^{2+}: \mathrm{Co}^{3+}$ ratio of the integrated intensity is $4: 2.7$, we obtain the expected $\mathrm{K}_{1,3}$ spectrum for a $\mathrm{Co}^{\mathrm{II}}{ }_{4} \mathrm{Co}^{\mathrm{III}}{ }_{2.7} \mathrm{PBA}$; an excellent agreement is observed with the experimental spectrum of CoPBA@20 ${ }^{\circ} \mathrm{C}$ (Fig. 5a). The $\mathrm{Co}^{2+}$ fraction is then determined as the ratio of the normalized spectrum of $\mathbf{C o}^{2+}-\mathbf{O}$ to the expected $\mathrm{K} \beta_{1,3}$ X-ray emission spectrum of $\mathrm{Co}_{4}^{\mathrm{II}}{ }_{4} \mathrm{Co}^{\mathrm{III}}{ }_{2.7}$ PBA or of Co-PBA@20 ${ }^{\circ} \mathrm{C}$ (Fig. 5b). For the two positions of the spectrometer chosen to record the K $\beta$-HERFD X-ray emission spectra (at $7649 \mathrm{eV}$ and $7650.6 \mathrm{eV}$ ), the value of the $\mathrm{Co}^{2+}$ fraction $\left(\gamma_{7649}\right.$ and $\gamma_{7650.6}$; Fig. $\left.5 b\right)$ is determined. They are then used to extract the pure $\mathrm{Co}^{2+}$ and $\mathrm{Co}^{3+}$ site-selective spectra $\left(S\left(\mathrm{Co}^{2+}\right)\right.$ and $\left.S\left(\mathrm{Co}^{3+}\right)\right)$ by a linear combination of the
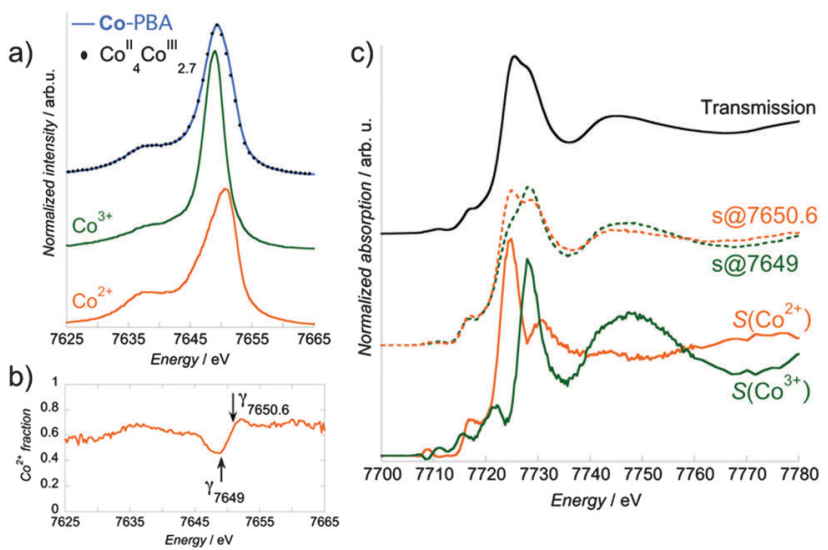

Fig. 5 Extraction of the $\mathrm{CO}^{2+}$ and $\mathrm{CO}^{3+}$ site-selective XANES spectra. (a) Normalized Co $K \beta_{1,3}$ emission line for the $\mathrm{Co}^{2+}-\mathrm{O}$ and $\mathrm{Co}^{3+}-\mathrm{C}$ references, and Co-PBA $\triangle 20{ }^{\circ} \mathrm{C}$. The dotted line on the upper curve represents the linear combination of the normalized $\mathrm{X}$-ray emission spectra of $\mathrm{Co}^{2+}-\mathrm{O}$ and $\mathrm{Co}^{3+}-\mathrm{C}$ so that the $\mathrm{Co}^{2+}: \mathrm{CO}^{3+}$ ratio of the integrated intensity is $4: 2.7\left(\mathrm{CO}_{4}{ }_{4} \mathrm{CO}^{\prime \prime \prime}{ }_{2.7}\right)$. (b) $\mathrm{Co}^{2+}$ fraction at room temperature, with the values for the two positions of the spectrometer $\left(\gamma_{7649}\right.$ and $\left.\gamma_{7650,6}\right)$. (c) Normalized Co K-edge XANES spectra of Co-PBA@2 $2{ }^{\circ} \mathrm{C}$ recorded in transmission mode (upper curve) and for the two positions of the spectrometer (s@7649, orange middle curve and s@7650.6 orange middle curve), with the extracted pure $\mathrm{Co}^{2+}\left(\mathrm{S}_{(} \mathrm{Co}^{2+}\right)$; orange lower curve) and $\mathrm{Co}^{3+}\left(\mathrm{S}_{\left(\mathrm{CO}^{3+}\right.}\right)$; green lower curve) contributions. 
measured K $\beta$-HERFD X-ray emission spectra (s@7649 and s@7650.6) (Fig. 5c):

$$
S\left(\mathrm{Co}^{2+}\right)=\frac{\left(1-\gamma_{7650.6}\right) \cdot \mathrm{s} @ 7649-\left(1-\gamma_{7649}\right) . \mathrm{s} @ 7650.6}{\gamma_{7649}-\gamma_{7650.6}}
$$

This equation corresponds to a standard deconvolution of a multi-component system and was already used in previous siteselective XAS investigations., ${ }^{8,11,17}$

In order to assess the reliability of this extraction procedure, additional XANES spectra in the transmission mode were recorded for two references: $\mathbf{C o}^{3+}-\mathbf{C}$ and $\mathbf{C o}^{2+}-\mathbf{N}$, where the Co ions are present in the same $\mathrm{O}_{\mathrm{h}} \mathrm{Co}^{3+}$ and $\mathrm{Co}^{2+}$ sites as those in Co-PBA@20 ${ }^{\circ} \mathrm{C}$. An excellent agreement is observed between the site-selective spectra of Co-PBA@20 ${ }^{\circ} \mathrm{C}$ and the related references in transmission mode (Fig. 6). This indicates that the extraction procedure is reliable and it was therefore applied to all measured temperatures.

\section{Evolution of the $\mathrm{Co}^{2+}$ and $\mathrm{Co}^{3+}$ contributions with temperature}

In the following text, we do not discuss the pre-edge features of the site-selective spectra since the selection of the Co $K \beta_{1,3}$ emission line to record the XANES spectrum may result in the modification of some spectral features in the pre-edge. ${ }^{18,31,32}$ The pre-edge measured using HERFD indeed corresponds to a constant emission energy cut in the resonant XES (RXES) plane $\mathrm{e}^{11,33,34}$ and it was shown that such a scan may show features that are not actual absorption features. ${ }^{35}$ The reliable interpretation of the HERFD pre-edge thus requires the measurement and careful analysis of the full RXES plane, ${ }^{11,35}$ which was beyond the scope of this study. However, it is to be noted that the main edge region of the spectrum (above the preedge features) should mainly be affected by sharpening as compared to a conventional XANES spectrum. This is due to the resolution that has the order of magnitude of the core hole lifetime. Detailed discussion about this point can be found in ref. 11 and 33-35.

The $\mathrm{Co}^{2+}$ and $\mathrm{Co}^{3+}$ site-selective XANES spectra of Co-PBA as a function of temperature and of exsitu are displayed in Fig. 7. At $20{ }^{\circ} \mathrm{C}$, the shape of the spectra is the signature of the $\mathrm{Co}^{3+}$

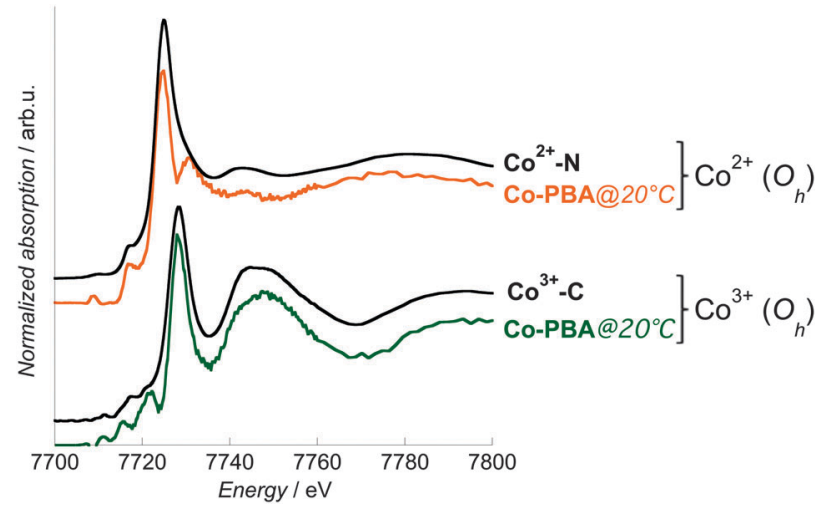

Fig. $6 \mathrm{CoK}$-edge $\mathrm{Co}^{2+}$ and $\mathrm{Co}^{3+}$ site-selective spectra of Co-PBA $a 20{ }^{\circ} \mathrm{C}$ (orange line: $\mathrm{Co}^{2+}$ pure spectrum; green line: $\mathrm{Co}^{3+}$ pure spectrum) and transmission spectra of $\mathrm{Co}^{2+}-\mathrm{N}$ and $\mathrm{Co}^{3+}-\mathrm{C}$ (black lines).
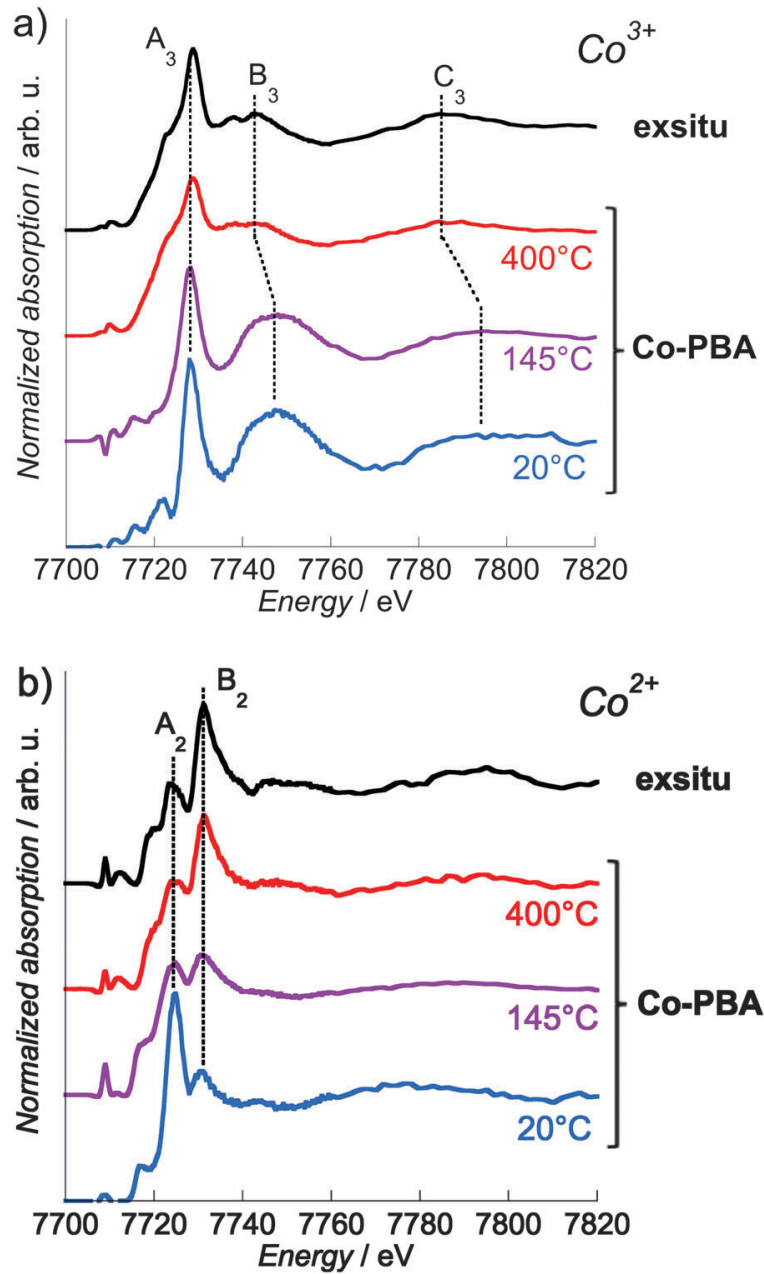

Fig. 7 Co K-edge $\mathrm{Co}^{3+}$ (a) and $\mathrm{Co}^{2+}$ (b) pure site-selective XANES spectra of exsitu and Co-PBA (measured in situ at $20^{\circ} \mathrm{C}, 145^{\circ} \mathrm{C}$ and $400{ }^{\circ} \mathrm{C}$ ).

(Fig. 6 and 7a) or $\mathrm{Co}^{2+}$ (Fig. 6 and 7b) ions in the two $\mathrm{O}_{\mathrm{h}}$ sites of the PBA structure. Both Co-PBA@400 ${ }^{\circ} \mathrm{C}$ and exsitu consists of $\mathrm{Co}_{3} \mathrm{O}_{4}$; their site-selective $\mathrm{Co}^{3+}$ (Fig. 7a) and $\mathrm{Co}^{2+}$ (Fig. 7b) spectra are the first experimental signature of the single $\mathrm{Co}^{2+}\left(\mathrm{T}_{\mathrm{d}}\right)$ and $\mathrm{Co}^{3+}\left(\mathrm{O}_{\mathrm{h}}\right)$ sites in the spinel structure. These experimental spectra of Co-PBA@400 ${ }^{\circ} \mathrm{C}$ and exsitu are also in quite good agreement with multiple-scattering calculations performed on $\mathrm{Co}_{3} \mathrm{O}_{4}$ by Jiang and Ellis. ${ }^{36}$

The pure $\mathrm{Co}^{2+}$ and $\mathrm{Co}^{3+}$ site-selective XANES spectra display significant changes with temperature (Fig. 7). In the case of $\mathrm{Co}^{3+}$ (Fig. 7a), the spectra at $20{ }^{\circ} \mathrm{C}$ and $145{ }^{\circ} \mathrm{C}$ are very close, indicating that this site of the PBA is not modified and that the $\mathrm{Co}^{3+}$ ion remains sixfold-coordinated to $\mathrm{CN}^{-}$ligands. At $400{ }^{\circ} \mathrm{C}$ the spectrum displays some modification, in particular for the $\mathrm{B}_{3}$ and $\mathrm{C}_{3}$ features. On the contrary the energy of the white line (7728.2 eV; peak $\mathrm{A}_{3}$ ) remains nearly constant. In $\mathrm{Co}_{3} \mathrm{O}_{4}$, the $\mathrm{Co}^{3+}$ cation is known to sit in the octahedral site, which is consistent with these spectral features observed at $400{ }^{\circ} \mathrm{C}$ and for exsitu. The high intensity of the $\mathrm{B}_{3}$ feature at $20{ }^{\circ} \mathrm{C}$ results from the significant multiple scattering (MS) in the $\mathrm{Co}^{3+}-\mathrm{CN}$ linkages. ${ }^{37-40}$ Its strong and abrupt intensity-decrease above 

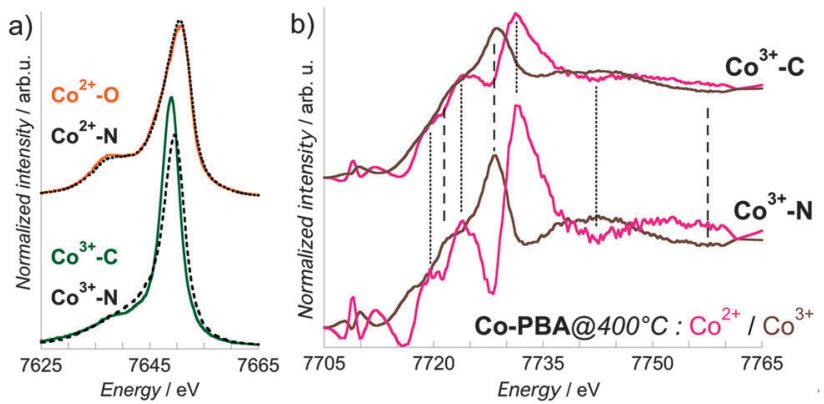

Fig. 8 (a) $\mathrm{Co} \mathrm{K} \beta_{1,3} \mathrm{X}$-ray emission spectra of the $\mathrm{Co}^{2+}$ (upper curves) and $\mathrm{Co}^{3+}$ (lower curves) references $\mathrm{Co}^{2+}-\mathrm{O}$ for a $\mathrm{CO}^{2+}-\mathrm{OH}_{2}$ bond, $\mathrm{Co}^{2+}-\mathrm{N}$ for a $\mathrm{CO}^{2+}-\mathrm{NC}$ bond, $\mathrm{Co}^{3+}-\mathrm{C}$ for a $\mathrm{Co}^{3+}-\mathrm{CN}$ bond and $\mathrm{Co}^{3+}-\mathrm{N}$ for a $\mathrm{Co}^{3+}-\mathrm{NC}$ bond. (b) Comparison of the $\mathrm{Co}^{2+}$ and $\mathrm{Co}^{3+}$ site-selective XANES spectra of Co-PBA $\left(400{ }^{\circ} \mathrm{C}\right.$ extracted using $\mathrm{Co}^{3+}-\mathrm{C}$ (upper curves) or $\mathrm{Co}^{3+}-\mathrm{N}$ (lower curves) as a reference for the +III oxidation state. The dotted (resp. dashed) lines are guides to compare the energy of the $\mathrm{Co}^{2+}$ (resp. $\mathrm{Co}^{3+}$ ) spectral features

$200{ }^{\circ} \mathrm{C}$ reveals the decomposition of the cyanide bridges already observed by previous thermodifferential and thermogravimetric analyses $^{21}$ and is consistent with the lower MS in $\mathrm{Co}_{3} \mathrm{O}_{4}$. The shift towards the lower energy of the $\mathrm{B}_{3}$ and $\mathrm{C}_{3}$ features at $400{ }^{\circ} \mathrm{C}$ also reflects the lengthening of the Co-to-ligand bond expected for the $\mathrm{Co}^{3+}-\mathrm{CN} \rightarrow \mathrm{Co}^{3+}-\mathrm{O}$ transformation, ${ }^{41,42}$ according to Natoli's rule. ${ }^{43}$ These observations indicate that the $\mathrm{Co}^{3+}$ site mainly undergoes a change in the chemical nature of the neighbours, i.e. the abrupt replacement of the six $\mathrm{C}$ neighbours by the six $\mathrm{O}$ neighbours above $200{ }^{\circ} \mathrm{C}$ following the cyanide bridge decomposition. ${ }^{21}$ In contrast, in the case of $\mathrm{Co}^{2+}$ (Fig. 7b), a continuous evolution of the spectra is observed upon heating: at $145^{\circ} \mathrm{C}$, the relative intensity of the $\mathrm{A}_{2}$ and $\mathrm{B}_{2}$ features is almost $1: 1$, and at $400{ }^{\circ} \mathrm{C}$ it is inverted with respect to the spectrum at $20{ }^{\circ} \mathrm{C}$. These spectral changes upon heating are consistent with the progressive transformation from $\mathrm{Co}(\mathrm{NC})_{4}\left(\mathrm{OH}_{2}\right)_{2}$ $\left(20{ }^{\circ} \mathrm{C}\right)$ to $\mathrm{Co}_{3} \mathrm{O}_{4}\left(400{ }^{\circ} \mathrm{C}\right)$, probably via a $\mathrm{Co}(\mathrm{NC})_{4}$ transient state $\left(145{ }^{\circ} \mathrm{C}\right)$. This transient state is supported by our previous thermogravimetric analyses, which showed the loss of water molecules above $90{ }^{\circ} \mathrm{C}^{21}$ In addition to the determination of the steps of the transformation, this clearly different behavior of the two sites also shows that it is possible with site-selective XAS (i) to discriminate between active and inert species and (ii) to monitor the active species during the transformation.

\section{Effect of the ligands}

In this proof-of-principle in situ study, the successful extraction of the pure $\mathrm{Co}^{2+}$ and $\mathrm{Co}^{3+}$ site-selective spectra justifies a posteriori the use of only two references and consequently the recording of the spectra for only two energies (positions) of the spectrometer. It is known that for a given oxidation and spin state, the $\mathrm{K} \beta_{1,3}$ lines are also sensitive to the nature of the ligand, ${ }^{11,12,19}$ as illustrated in Fig. 8, where in addition to $\mathrm{Co}^{2+}-\mathbf{O}\left(\mathrm{Co}^{2+}(\mathrm{HS})-\mathrm{OH}_{2}\right.$ bond $)$ and $\mathbf{C o}^{3+}-$ $\mathbf{C}\left(\mathrm{Co}^{3+}(\mathrm{LS})-\mathrm{CN}\right.$ bond $)$, two more references are displayed: $\mathrm{Co}^{2+}-\mathbf{N}$ for an average of four $\mathrm{Co}^{2+}(\mathrm{HS})-\mathrm{NC}$ and two $\mathrm{Co}^{2+}(\mathrm{HS})-\mathrm{OH}_{2}$ bonds, and $\mathbf{C o}^{3+}-\mathbf{N}^{24}$ for an average of five $\mathrm{Co}^{3+}(\mathrm{LS})-\mathrm{NC}$ and one $\mathrm{Co}^{3+}(\mathrm{LS})-$ $\mathrm{OH}_{2}$ bonds. In the case of $\mathrm{Co}^{2+}$ (Fig. 7a, upper curves), the two $\mathrm{K} \beta_{1,3}$ $\mathrm{X}$-ray emission spectra are almost superimposed, as expected by the close covalency of the $\mathrm{Co}^{2+}(\mathrm{HS})-\mathrm{O}$ and $\mathrm{Co}^{2+}(\mathrm{HS})-\mathrm{N}$ bonds. On the contrary, the $\mathrm{K} \beta_{1,3}$ X-ray emission spectra of $\mathbf{C o}^{3+}-\mathbf{N}$ and $\mathbf{C o}^{3+}-\mathbf{C}$ (Fig. 8a, lower curves) display significant differences, both in the spectral shape and in the energy of the maximum. This liganddependence of the $\mathrm{K} \beta_{1,3}$ X-ray emission spectrum makes preferable the choice of references with a covalency of the Co-to-ligand bond as close as possible as in the chemical species under study. Nevertheless, we observed here that whatever the choice of the reference compound, the position of the features of the siteselective spectra is not modified and that only their relative intensity varies (Fig. 8b). Measurements for as many spectrometer positions as required by the different oxidation state - spin state covalency sites possibly found in the compound under investigation should strengthen the results. However, even if references are chosen only from the known states of the material under investigation, reliable results are still obtained from the site-selective XANES spectra. This point has to be noted, since the transient (and possibly the final) species are usually unknown.

\section{Conclusions}

We present herein the first in situ site-selective XAS study, with an emphasis on the XANES part of the spectrum. We successfully managed to singly resolve the evolution of the $\mathrm{Co}^{2+}$ and $\mathrm{Co}^{3+}$ sites during the calcination of Co-PBA into $\mathrm{Co}_{3} \mathrm{O}_{4}$. The spectra of $\mathrm{Co}^{2+}\left(\mathrm{T}_{\mathrm{d}}\right)$ and $\mathrm{Co}^{3+}\left(\mathrm{O}_{\mathrm{h}}\right)$ ions in $\mathrm{Co}_{3} \mathrm{O}_{4}$ were also singly recorded for the first time. Obtaining pure spectra for all the sites demonstrates again the power of site-selective XANES to investigate very complex samples such as the spinel family, which presents direct and inverse spinels as well as solid solutions. In addition, herein we showed that site-selective XANES experiments can innovatively be trustfully performed in situ, which opens new perspectives for the study of chemical transformation or materials under working conditions (catalytic systems, biological systems, materials used for data storage, battery, renewable energies, etc.).

\section{Acknowledgements}

The authors warmly thank the ID26 beamline of the ESRF for the loan of their Ge(111) crystals, E. Lahera and I. Kieffer (OSUG and FAME beamline, Grenoble, France) for technical support and fruitful discussion. The gas-blowing furnace was borrowed to the Sample Environment Support Service of the ESRF. This work was supported by the C'Nano network via contract AF2012-a1-12 EPIMAGE. The adaptation of the spectrometer at $1 \mathrm{~m}$ was supported by a grant from Labex OSUG@2020 (Investissement d'avenir - ANR10 LABX56).

\section{Notes and references}

1 C. Garino, E. Borfecchia, R. Gobetto, J. van Bokhoven and C. Lamberti, Coord. Chem. Rev., 2014, 277-278, 130-186.

2 A. Boubnov, H. W. P. Carvalho, D. E. Doronkin, T. Günter, E. Gallo, A. J. Atkins, C. R. Jacob and J.-D. Grunwaldt, J. Am. Chem. Soc., 2014, 136, 13006-13015. 
3 A. Gorczyca, V. Moizan, C. Chizallet, O. Proux, W. Del Net, E. Lahera, J.-L. Hazemann, P. Raybaud and Y. Joly, Angew. Chem., Int. Ed., 2014, 53, 1-5.

4 F. F. Amalraj and D. Aurbasch, J. Solid State Electrochem., 2011, 15, 877-890.

5 J. Singh, C. Lamberti and J. A. van Bokhoven, Chem. Soc. Rev., 2010, 39, 4754-4766.

6 M. W. Kanan, J. Yano, Y. Surendranath, M. Dinca, V. K. Yachandra and D. G. Nocera, J. Am. Chem. Soc., 2010, 132, 13692-13701.

7 J. B. Leriche, S. Hamelet, J. Shu, M. Morcrette, C. Masquelier, G. Ouvrard, M. Zerrouki, P. Soudan, S. Bellin, E. Elkaïm and F. Baudelet, J. Electrochem. Soc., 2010, 157, A606-A610.

8 P. Glatzel, L. Jacquamet, U. Bergmann, F. de groot and S. Cramer, Inorg. Chem., 2002, 41, 3121-3127.

9 F. de Groot, Top. Catal., 2000, 10, 179-186.

10 M. Grush, G. Christou, K. Hämäläinen and S. Cramer, J. Am. Chem. Soc., 1995, 117, 5895-5896.

11 P. Glatzel and U. Bergmann, Coord. Chem. Rev., 2005, 249, 65-95.

12 U. Bergmann, C. R. Thorne, T. J. Collins, J. M. Workman and S. P. Cramer, Chem. Phys. Lett., 1999, 30, 119-124.

13 N. Lee, T. Petrenko, U. Bergmann, F. Neese and S. DeBeer, J. Am. Chem. Soc., 2010, 132, 9715-9727.

14 R. Alonso-Mori, E. Paris, G. Giuli, S. G. Eeckhout, M. Kavcic, M. Zitnik, K. Bucar, L. G. M. Pettersson and P. Glatzel, Inorg. Chem., 2010, 49, 6468-6473.

15 U. Bergmann and P. Glatzel, Photosynth. Res., 2009, 102, 255-266.

16 G. Vanko, T. Neisius, G. Molnar, F. Renz, S. Karpati, A. Shukla and F. de Groot, J. Phys. Chem. B, 2006, 110, 11647-11653.

17 T.-J. Kühn, J. Hormes, N. Matoussevitch, H. Bönnemann and P. Glatzel, Inorg. Chem., 2014, 53, 8367-8375.

18 T.-J. Kühn, W. Caliebe, N. Matoussevitch, H. Bönnemann and J. Hormes, Appl. Organomet. Chem., 2011, 25, 577-584.

19 C. Lambertz, P. Chernev, K. Klingan, N. Leidel, K. Sigfridsson, T. Happe and M. Haumann, Chem. Sci., 2014, 5, 1187-1203.

20 N. Leidel, P. Chernec, K. Havelius, S. Ezzaher, S. Ott and M. Haumann, Inorg. Chem., 2012, 51, 4546-4559.

21 V. Trannoy, E. Delahaye, G. Fornasieri, P. Beaunier and A. Bleuzen, C. R. Chim., 2014, 17, 512-520.

22 H. J. Buser, D. Schwarzenbach, W. Peter and A. Lüdi, Inorg. Chem., 1977, 16, 2704-2710.

23 A. Lüdi and H. U. Güdel, Structure and Bonding, Spinger, Berlin, 1973, vol. 1, p. 21.

24 A. Bleuzen, C. Lomenech, V. Escax, F. Villain, F. Varret, Ch. Cartier dit Moulin and M. Verdaguer, J. Am. Chem. Soc., 2000, 122, 6648-6652.

25 I. Llorens, E. Lahera, W. Del Net, O. Proux, A. Braillard, J.-L. Hazemann, A. Prat, D. Testemale, Q. Dermigny, F. Gelebart, M. Morand, A. Shulkla, N. Bardou, O. Ulrich,
S. Arnaud, J.-F. Bérar, N. Boudet, B. Caillot, P. Chaurand, J. Rose, E. Doelsch, Ph. Martin and P. L. Solari, Rev. Sci. Instrum., 2012, 83, 063104.

26 Nanoparticles from the gas phase: Formation, Structure, Properties, ed. A. Lorke, M. Winterer, R. Schmechel and C. Schulz, Springer-Verlag, Berlin Heidelberg, 2012, p. 69.

27 J. T. Thienprasert, S. Klaithong, A. Niltharach, A. Worayingyong, S. Na-Phattalung and S. Limpijumnong, Curr. Appl. Phys., 2011, 11, S279-S284.

28 G. Vanko, A. Bordage, P. Glatzel, E. Gallo, M. Rovezzi, W. Gawelda, A. Galler, Ch. Bressler, G. Doumy, A.-M. March, E. P. Kanter, L. Young, S. H. Southworth, S. E. Canton, J. Uhlig, G. Smolentsev, V. Sundström, K. Haldrup, T. B. van Driel, M. M. Nielsen, K. S. Kjaer and H. T. Lemke, J. Electron Spectrosc. Relat. Phenom., 2013, 188, 166-171.

29 G. Vanko, P. Glatzel, V.-T. Pham, R. Abela, D. Grolimund, C. N. Borca, S. L. Johnson, C. J. Milne and Ch. Bressler, Angew. Chem., Int. Ed., 2010, 49, 5910-5912.

30 J. Badro, J.-P. Rueff, G. Vanko, G. Monaco, G. Fiquet and F. Guyot, Science, 2004, 305, 383-386.

31 G. Vanko, F. M. F. de Groot, S. Huotari, R. J. Cava, T. Lorenz and M. Reuther, 2008, arXiv:0802.2744v1.

32 D. Friebel, M. Bajdich, B. S. Yeo, M. W. Louie, D. J. Miller, H. Sanchez Casalongue, F. Mbuga, T.-C. Weng, D. Nordlund, D. Sokaras, R. Alonso-Mori, A. T. Bell and A. Nilsson, Phys. Chem. Chem. Phys., 2013, 14, 17460-17467.

33 P. Glatzel, T.-C. Weng, K. Kvashnina, J. Swarbrick, M. Sikora, E. Gallo, N. Smolentsev and R. Alonso-Mori, J. Electron Spectrosc. Relat. Phenom., 2013, 188, 17-25.

34 M. Rovezzi and P. Glatzel, Semicond. Sci. Technol., 2014, 29, 023002.

35 P. Glatzel, M. Sikora, G. Smolentsev and M. FernandezGarcia, Catal. Today, 2009, 145, 294-299.

36 T. Jiang and D. E. Ellis, J. Mater. Res., 1996, 11, 2242-2256.

37 A. Kuzmin and J. Purans, J. Phys.: Condens. Matter, 1993, 5, 267-282.

38 M. Giorgetti, M. Berrettoni, A. Filipponi, P. J. Kulesza and R. Marassi, Chem. Phys. Lett., 1997, 275, 108-112.

39 T. Yokoyama, T. Ohta, O. Sato and K. Hashimoto, Phys. Rev. B: Condens. Matter Mater. Phys., 1998, 58, 8257-8266.

40 Ch. Cartier dit Moulin, F. Villain, A. Bleuzen, M.-A. Arrio, Ph. Sainctavit, C. Lomenech, V. Escax, F. Baudelet, E. Dartyge, J.-J. Gallet and M. Verdaguer, J. Am. Chem. Soc., 2000, 122, 6653-6658.

41 P. G. Radaelli and S.-W. Cheong, Phys. Rev. B: Condens. Matter Mater. Phys., 2002, 66, 094408.

42 N. A. Curry and W. A. Runciman, Acta Crystallogr., 1959, 12, 674-677.

43 C. Natoli, in EXAFS and Near-Edge Structure III, Springer proceedings in physics 2, ed. B. H. K. O. Hodgson and J. Penner-Hahn, Springer-Verlag, 1984, pp. 38-42. 